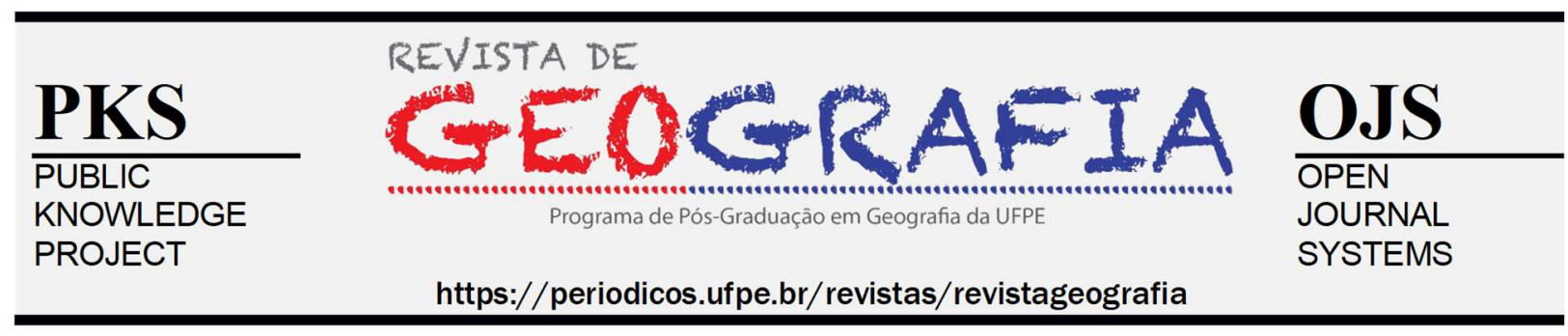

\title{
AS CIDADES E SUAS REPRESENTAÇÕES: CRUZANDO OLHARES DOS (AS) ESTUDANTES SOBRE SÃO GONÇALO, NITERÓI E SEROPÉDICA (RIO DE JANEIRO, BRASIL)
}

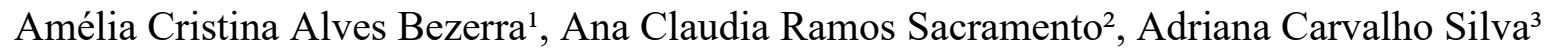

\begin{abstract}
${ }^{1}$ Professora Associada da Universidade Federal Fluminense. E-mail: amelliacristina@uol.com.br. http://orcid.org/00000002-9405-1284

2 Professora UERJ-FFP no Departamento de Geografia. E-mail: anaclaudia.sacramento@hotmail.com. http://orcid.org/0000-0002-3006-5310

${ }^{3}$ Professora Adjunta da Universidade Federal Rural do Rio de Janeiro - UFRRJ, Departamento de Teoria e Planejamento de Ensino. Doutora em Geografia pela UFF. E-mail: adrianacarvalhosilva@gmail.com. http://orcid.org/0000-0002-41135142
\end{abstract}

Artigo recebido em 24/05/2020 e aceito em 17/11/2020

\begin{abstract}
RESUMO
A escola é um espaço estratégico de reflexão sobre o urbano e a cidade. Para o ambiente escolar convergem os sujeitos e suas narrativas dos espaços em que vivem. Nesse sentido, este artigo é resultante de um esforço coletivo para pensar as diferentes leituras e representações dos estudantes sobre suas cidades. Esta investigação envolve três Instituições de ensino superior - Universidade Federal Fluminense (UFF), Faculdade de Formação de Professores da Universidade do Estado do Rio de Janeiro (Ffp-Uerj) e Universidade Federal Rural do Rio de Janeiro (UFRRJ) - as três cidades onde estão localizadas, respectivamente - Niterói, São Gonçalo e Seropédica - e as escolas de educação básica participantes da pesquisa e situadas nas referidas cidades. Para o desenvolvimento da investigação lançamos mão da metodologia mista, em que tanto os dados quantitativos quanto qualitativos são produzidos simultaneamente. Neste artigo apresentaremos e discutiremos as respostas atribuídas a quatro perguntas semiestruturadas, as duas primeiras questionavam a representação da cidade, de maneira mais ampla, e as duas outras, mais específicas, sobre a relação dos(as) estudantes com as cidades onde vivem. Partindo dessa pesquisa, conseguimos cruzar os diversos olhares e representações, permitindo identificar as singularidades e, ao mesmo tempo, as universalidades que orientam a forma como as cidades são compreendidas pelos(as) estudantes que compõe o espaço escolar.
\end{abstract}

Palavras-chave: Representação. Cidade. Estudantes.

\section{THE CITIES AND YOUR REPRESENTATIONS: CROSSING THE STUDENTS VIEWS ON SÃO GONÇALO, NITERÓI AND SEROPÉDICA (RIO DE JANEIRO, BRASIL)}

\begin{abstract}
The school is a strategic space for reflection about the urban and the city. For the school environment, the subject and your narratives converge about the spaces in which they live. In this respect, this article is the result of a collective effort to think about the different readings and representations of students about their cities. This investigation envolves three institutions - Federal Fluminense University (UFF), Faculty of Teacher Education-State University of Rio de Janeiro (FfpUerj) and Federal Rural University of Rio de Janeiro (UFRRJ) - three cities where are located respectively: Niterói, São Gonçalo e Seropédica - and the schools to basic education participate of this investigation located in those cities. For the development of the investigation, we use the mixed methodology, in which both quantitative and qualitative datas are
\end{abstract}


produced at the same time. In this article we will discuss the results of solving a questionnaire consisting of four semistructured questions about of students' apprehension about the city, in general way, about the relationship of the students with the cities where they live. Based on this research, we got to cross the differents views and representations', allowing to identify the singularities and, the same time, the universalities that guide the way how the city are understood by the students who make the school space.

Keywords: Representation. City. Students.

\title{
LAS CIUDADES Y SUS REPRESENTACIONES: CRUZANDO LAS MIRADAS DE LOS (LAS) ESTUDIANTES SOBRE SÃO GONÇALO, NITERÓI E SEROPÉDICA (RIO DE JANEIRO, BRASIL)
}

\begin{abstract}
RESUMEN
La escuela es un espacio estratégico para la reflexión sobre la urbe e la ciudad. Para el ambiente escolar converge los sujetos y sus narrativas de los espacios en que viven. En eso sentido, esto artículo es resultante de un esfuerzo colectivo para pensar la diferentes lecturas y representaciones de los estudiantes sobre sus ciudades. Esta investigación involucra tres instituciones de enseñanza superior - Universidad Federal Fluminense (UFF), Facultad de Formación de Profesorado - Universidad del Estado del Rio de Janeiro (Ffp-Uerj) y Universidad Federal Rural del Rio de Janeiro (UFRRJ) - as tres ciudades donde están ubicadas, respectivamente - Niterói, São Gonçalo e Seropédica - y las escuelas de educación básica participantes de la investigación y situadas en las referidas ciudades. Para el desarrollo de la investigación pensamos la metodología mixta, en que tanto los datos cuantitativos cuanto cualitativos son producidos simultáneamente. En esto artículo presentaremos y discutiremos las respuestas de cuatro preguntas semiestructuradas, las dos primeras cuestionaban la representación de la ciudad, de manera más larga, e las dos otras, más específicas, sobre la relación de los (las) estudiantes con las ciudades onde viven. Por esta investigación, conseguimos cruzar las diferentes miradas y representaciones de ellos, permitiendo identificar las singularidades y, al mismo tiempo, las universidades que guían la forma como las ciudades son comprendidas por los (las) estudiantes que componen el espacio escolar.
\end{abstract}

Palabras-llaves: Representación. Ciudad. Estudiantes.

\section{INTRODUÇÃO: O TEMA, O PERCURSO E OS SUJEITOS}

O presente artigo é resultado de uma pesquisa que reúne diferentes leituras e representações de estudantes do ensino fundamental que residem nas cidades da região metropolitana do Rio de Janeiro - Niterói, Seropédica e São Gonçalo. Em cada uma dessas cidades, estão localizadas Instituições de ensino superior que exercem um importante papel na formação de profissionais de diversas áreas. Dentre elas, fizeram parte da pesquisa a Universidade Federal Fluminense (UFF), em Niterói; a Faculdade de Formação de Professores - Universidade do Estado do Rio de Janeiro (FfpUerj), em São Gonçalo; e a Universidade Federal Rural do Rio de Janeiro (UFRRJ), em Seropédica.

Estas Universidades formam licenciandos(as) que atendem às redes de ensino básico em níveis federal, estadual, municipal e privado em toda região metropolitana da Rio de Janeiro. Logo abaixo, na figura I, é possível identificar a localização de tais cidades. 
Figura I: Mapa de localização de Niterói, Seropédica e Niterói (RJ).

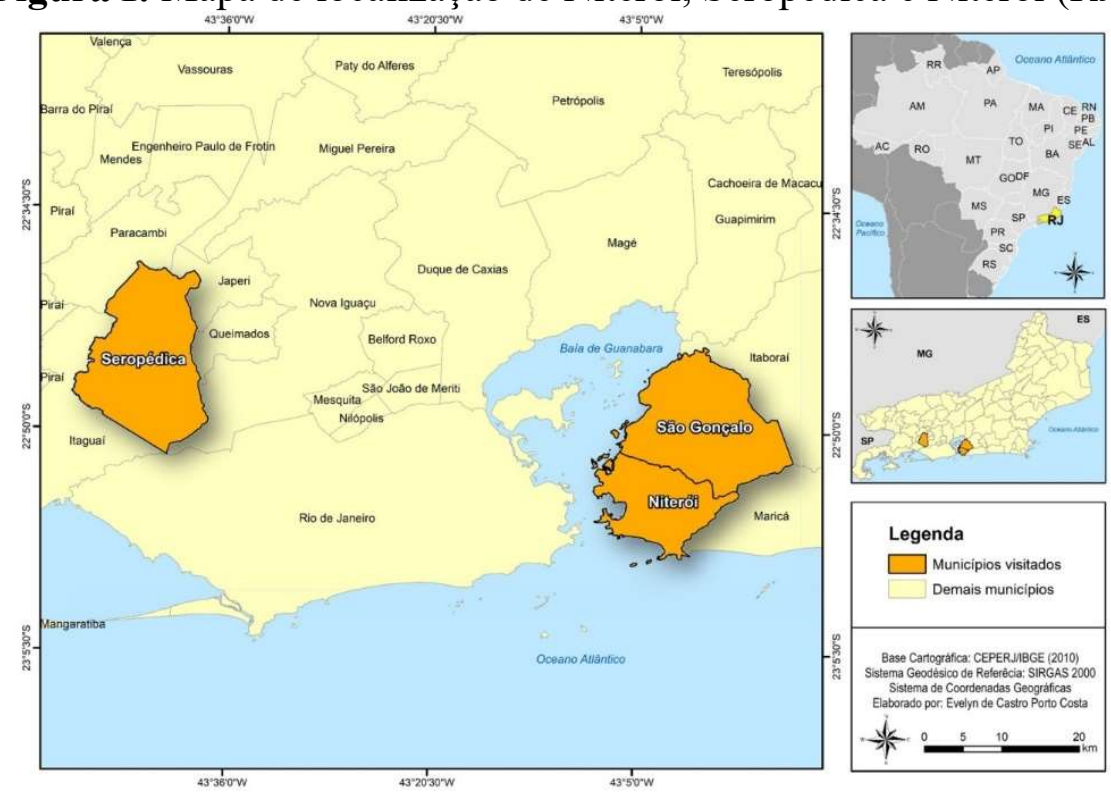

Fonte: Organizado por Evelyn Castro (2019)

Embora componham, junto a outras cidades, a área metropolitana do Rio de Janeiro, São Gonçalo, Seropédica e Niterói apresentam formação e dinâmicas socioespaciais cotidianas bem diferentes. Pensá-las e, sobretudo, compreender como os estudantes das escolas apreendem e representam tais cidades é bem instigante e necessário, pois, como dialogar com o cotidiano dos sujeitos em formação sem pensar os espaços onde vivem?

Tais inquietações resultaram numa pesquisa denominada Leituras sobre as espacialidades das cidades e suas representações na sala de aula. Tal pesquisa foi aprovada pela "Fundação de Amparo à Pesquisa do Estado do Rio de Janeiro" (FAPERJ), em 2016 e reuniu três professoras das Instituições de ensino superior acima mencionadas, bem como licenciandos(as) e professores(as) de geografia da rede pública tanto estadual como municipal ${ }^{1}$. Um dos objetivos da pesquisa visava

compreender as apreensões e representações socioespaciais dos estudantes da cidade onde vivem e como estas podem contribuir para discussão desse tema nas aulas de geografia.

\footnotetext{
${ }^{1}$ Para realização dessa pesquisa, contamos com a parceria de professoras da rede pública de ensino. Em Niterói, houve a colaboração da professora Simone Antunes Ferreira, docente do Instituto Ismael Coutinho. Em São Gonçalo, desenvolvemos parcerias com as professoras Aline Campos Mello da Escola Estadual Lauro Correa e Jupiara de Jesus da Silva (In memoriam) CIEP 041- Vital Brazil Em Seropédica, a pesquisa foi desenvolvida em diálogo com a professora Maria Luiza Oliveira de Francisco, docente do CAIC Paulo DACORSO Filho.
} 
A cidade tem sido um tema de investigação tanto no campo da geografia urbana como por aqueles(as) envolvidos(as) com o ensino e a pesquisa sobre a geografia escolar. A afirmação e ampliação destes estudos e pesquisas se justificam na medida em que é na cidade, como afirma Lefebvre (2001), que se materializa a vida cotidiana. É nela onde os objetos ganham forma e conteúdo e onde as histórias são construídas e contadas, possibilitando a leitura de diferentes dimensões das espacialidades vividas.

A escola, neste contexto, assume um papel estratégico como espaço de reflexão sobre o urbano, pois, convergem para o ambiente escolar, narrativas, estórias e cotidianos que conformam e são conformados por meio da vivência na cidade. Desse modo, a escola e, especificamente, o professor assumem a função de identificar, conhecer e analisar os diferentes olhares sobre a cidade, e, a partir destes construírem os processos de mediação dos conteúdos geográficos que são abordados em sala de aula. Vale a pena lembrar que, nesse processo de mediação, o professor também possui suas representações.

Portanto, no processo de mediação didática aproximam-se e afastam-se diversas representações que são constituídas nas diferentes dimensões escalares, desde aquelas que os(as) estudantes produzem na relação com os espaços em que habitam, passando por outras as quais permeiam os discursos construídos sobre a cidade, seja no âmbito da gestão pública, seja na linguagem midiática ou ainda no material didático, afinal de contas o currículo produz representações.

Stuart Hall (2016), ao pensar as representações, destaca o papel da linguagem na sua construção. Ele aponta que os sentidos são criados e perpassados por intermédio da linguagem verbal e/ou não verbal. Comunicar-se com o outro é entendê-lo de alguma forma e isto pode acontecer para além da linguagem verbal. Desta forma, argumenta que a representação [..] "é uma parte essencial do processo pelo qual os significados são produzidos compartilhados entre os membros de uma cultural. Representar envolve o uso da linguagem, de signos e imagens que significam ou representam objetos" [..] (HALL, 2016, p.15).

A discussão sobre o conceito de representação está presente no livro La presencia y la ausência: Contribución a la teoría de las representaciones de Henri Lefebvre (1983). Nesta obra, são acionadas as dimensões do vivido (práticas de representação) e do concebido (representação do espaço), para pensar as representações. Tanto Stuart Hall quanto Henri Lefebvre, a partir das suas reflexões, ajudam no entendimento de que a linguagem e a dimensão espacial são referências importantes para pensar as representações.

O presente artigo é uma tentativa de aproximar os olhares e representações dos estudantes acerca das cidades de Niterói, São Gonçalo e Seropédica. Os resultados presentes neste artigo são 
uma parte da pesquisa que ainda está em curso. Organizamos o texto em três momentos: O primeiro deles traz uma breve reflexão sobre o debate da cidade na geografia, bem como os referenciais que alguns autores têm acionado para pensar as representações. Ainda nesse momento apresentamos o percurso da pesquisa. Seguindo, no segundo tópico, expomos e discutimos as representações dos estudantes sobre as cidades de Niterói, São Gonçalo e Seropédica e, por último, as considerações finais.

\section{A CIDADE, AS REPRESENTAÇÕES E OS CAMINHOS DA PESQUISA}

As trajetórias realizadas pelos(as) estudantes em seu cotidiano, entre a escola, a casa e também em outros espaços como, por exemplo, em visita à casa de um parente ou de um amigo, em passeio ao shopping ou ida à consulta médica, entre outros movimentos na cidade, nos revelam questões que envolvem a apropriação e uma leitura dos espaços vividos. Porto-Gonçalves (2006) afirma que as diferentes configurações espaciais permeiam e são permeadas pelas subjetividades de cada sujeito. Tal assertiva permite teorizar em como ocorrem os processos de subjetivação das experiências espaciais e como contribuem para construção dos olhares sobre as cidades. Estas experiências não são abordadas no currículo e, em específico, nos livros didáticos, uma vez que estes instrumentos pedagógicos tratam os espaços com um viés homogêneo e universal.

Apesar da unilateralidade conceitual dos instrumentos didáticos supracitados, de modo inegável, são importantes para o trato dos conceitos de cidade e do urbano no espaço escolar, uma vez que são teoricamente fundamentados pela orientação de reflexões e debates fomentados no âmbito acadêmico. Infelizmente, o que é veiculado nos materiais didáticos não dá conta de analisar as especificidades do cotidiano das pequenas e médias cidades ou transpor e tencionar o debate acadêmico para o que é vivenciado pelos alunos, por isso se faz necessária a mediação didática. Essa mediação é permeada pelos saberes dos professores(as), dentre os quais se destacam aqueles adquiridos na formação inicial, ou seja, no âmbito acadêmico e ainda pelas suas vivencias cotidianas.

No plano acadêmico da Geografia, há vários trabalhos que versam sobre as concepções de urbano e da cidade. Na tentativa de registrar sistematicamente os temas que foram tratados pelos(as) estudiosos(as) e pesquisadores(as) Abreu (1994) construiu uma importante reflexão. Nesta, apresentou as concepções e temas que fomentaram as leituras sobre a cidade e o urbano, especialmente na década de noventa. Nesse período existiam poucos trabalhos abordando tais temas no ambiente escolar.

Ainda como contribuição de Abreu (1999, 2010), destacam-se as reflexões em torno da produção do espaço da cidade do Rio de Janeiro. Seu diálogo com a história permitiu compreender 
as mudanças ocorridas na cidade, possibilitando analisar o processo de segregação social e, especialmente, o papel do Estado na configuração do espaço urbano durante a formação da própria cidade.

Por sua vez, as reflexões de Milton Santos (2005) sobre o conceito de espaço e ainda sobre a urbanização brasileira contribuíram para pensar a noção de cidade no Brasil. Dentre as características da urbanização brasileira, o referido autor destaca a modernização do espaço rural, bem como o processo de metropolização (oligopolização). Neste processo de metropolização, muitas cidades ficaram enredadas e ofuscadas pelo controle da metrópole.

Apurar e visibilizar a dinâmica socioespacial de cada cidade que orbita em torno das metrópoles que detém o poder e o aparato técnico-informacional ajuda a compreender e mensurar as referências sobre as noções de cidade construídas e consolidadas no Brasil. A exposição deste conhecimento é de suma importância para a composição dos saberes curriculares da geografia que se produz na sala de aula.

Desse modo, pensar as cidades brasileiras, suas singularidades, seus processos socioespaciais são imprescindíveis para a produção do saber geográfico na sala de aula. Todavia, é preciso lembrar que tais dinâmicas urbanas são orientadas por processos mais globais, sendo necessário alicerçar reflexões num plano mais teórico. Nesse sentido, destaca-se a obra de Lefebvre (2001) que se consolidou como uma referência para pensar-a produção do espaço e, em específico, a cidade.

As reflexões teóricas destes autores conduzem a afirmar que a maneira como se compreende o espaço é um ponto de partida para o entendimento da ideia cidade. Como materialização das relações sociais, a concepção de espaço é um produto histórico e social que reúne tanto as ações das firmas (empresas globais e locais que atuam, a partir da lógica do mercado) como ações das Instituições (Estado, movimentos sociais e organizações não governamentais). Também reúne as ações humanas, pois os homens que por meio de suas ações e práticas cotidianas produzem e imprimem sentidos e significados ao espaço. Nesse sentido, Santos (1996) argumenta que a concepção de espaço é formada, portanto, por um conjunto indissociável, solidário e contraditório dos sistemas de objetos (materialidade) e sistemas de ações (as relações sociais).

Assim, as noções de espaço e, especificamente, a cidade - como uma das suas expressões são, ao mesmo tempo, um produto das relações político-econômicas. Quando se transportam do plano conceptual para o plano da realidade, o espaço e a cidade tornam-se, por excelência, instrumentos de poder, cujas disputas territoriais se materializam entre os diferentes agentes - empresas, Estados, movimentos sociais e os demais grupos. Ainda em relação à cidade, é também produto das 
experiências e das práticas espaciais cotidianas que se subjetivam e produzem memórias e identidades com os lugares de vivência.

As dimensões da experiência e das identidades compõem o entendimento que Massey (2008) elabora sobre o espaço. Compreendido como um produto de inter-relações, o espaço é como uma esfera de possibilidades da existência da multiplicidade. No espaço, coexistem distintas trajetórias e uma simultaneidade de estórias. Esta perspectiva de espaço dialoga com a concepção de Lefebvre (2001), para quem toda cidade tem uma história das pessoas e de grupos que a constroem em consonância com as necessidades e as condições históricas de cada época. Sendo assim, é concebida através das práticas socioespaciais que se configuram em diferentes escalas e contextos. Segundo este autor,

(...) Se há uma produção da cidade e das relações sociais na cidade, é uma produção e reprodução de seres humanos por seres humanos, mais do que uma produção de objetos. A cidade tem uma história: ela é a obra de uma história, isto é, de pessoas e de grupos bem determinados que realizam essa obra nas condições históricas (LEFEBVRE, 2001, p. 46-47).

As experiências com a cidade, com os espaços vividos, compõem uma das dimensões da representação que é permeada por outras, a exemplo das narrativas curriculares e midiáticas. Apreendê-las e compreendê-las torna-se indispensável aos professores(as) e ao estudante de geografia. Ao depreender o conceito de representação, Lefebvre (1983) ressalta a contribuição d filosofia para o desdobramento de debates sobre o tema, afirmando que o conceito é adotado pela filosofia sobrepondo uma tríade conceitual de "o representado", “o representante" e "a representação". Lefebvre, destaca ainda que as representações:

[...] Não se distinguem em verdadeiro e falso, mas em estáveis e móveis, reativos e superáveis; em alegorias - figuras tópicas redundantes e repetitivas - e em estereótipos incorporados "de maneira sólida em espaços e instituições". (LEFEBVRE, 1983, p.24.)

Ademais, pode-se observar uma aproximação entre o conceito de representação e ideologia, embora as mesmas não sejam correspondentes. As representações não podem ser reduzidas ao plano daquilo que é comunicado, apesar de compô-la, e nem a seu apoio social, como é o caso das ideologias. Nesse sentido, não podem ser classificadas como falsas ou verdadeiras, pois "são verdadeiras como respostas aos problemas reais e falsas como dissimuladoras das finalidades reais" (LEFEBVRE, 1983, apud BEZERRA, 2006, p.70).

Ainda com indagações como "Quem gera ou produz as representações? ”, "De onde elas emergem?”, “Quem as percebe e as recebe?", “Que sujeitos e o que fazem com elas?” e “É o sujeito 
individual e/ou social que produz as representações?"; Lefebvre (1983, apud BEZERRA, 2006) desenvolve seus pensamentos teóricos para construção das representações.

$\mathrm{Na}$ tentativa de entender melhor tais questões, especialmente, no que se refere a cidade, mergulhamos no universo dos estudantes das escolas. Para tanto, lançamos mão da metodologia mista que envolve um conjunto de metodologias qualitativa e quantitativa que, uma vez combinadas, permitem ampliar as reflexões e análises.

\begin{abstract}
Os métodos mistos combinam os métodos predeterminados das pesquisas quantitativas com métodos emergentes das qualitativas, assim como questões abertas e fechadas, com formas múltiplas de dados contemplando todas as possibilidades, incluindo análises estatísticas e análises textuais. Neste caso, os instrumentos de coleta de dados podem ser ampliados com observações abertas, ou mesmo, os dados censitários podem ser seguidos por entrevistas exploratórias com maior profundidade. No método misto, o pesquisador baseia a investigação supondo que a coleta de diversos tipos de dados garanta um entendimento melhor do problema pesquisado (CRESWELL, 2007, p. 34-35 apud FARRA, LOPES, 2013, p. 70).
\end{abstract}

Adotamos, desse modo, a utilização da estratégia mista de triangulação concomitante, que é resultante dos dados quantitativos e qualitativos coletados simultaneamente, para que, depois, possam ser analisados e, quando necessário, comparados com o objetivo de avaliar quais são as convergências e as diferenças (SANTOS et al., 2017, p. 4). Essa triangulação de dados é importante, para que a análise interpretativa possa ser realizada por meio de diferentes planos.

A fim de identificar as representações que os(as) estudantes carregam sobre as cidades pesquisadas, organizamos um questionário composto, inicialmente, de quatro perguntas semiestruturadas. As duas primeiras discorriam sobre suas apreensões acerca da cidade, de uma maneira mais geral, e as duas questões, mais específicas, sobre a relação dos estudantes com as cidades em que vivem. Seguem as questões: i) Para você, a cidade é ...?” ii)“Para você, Seropédica/Niterói/São Gonçalo é ...?" iii) “O maior problema de sua cidade é....?”iv) "O que você gosta na sua cidade...?

Estas questões foram aplicadas nas escolas onde trabalham os(as) professores(as) envolvidos(as) com o projeto, dentre as quais destacamos o Instituto de Educação Professor Ismael Coutinho (IEPIC), no bairro de São Domingues localizado em Niterói, o Centro de Atenção Integral à Criança e ao Adolescente (CAIC Paulo Darcoso Filho), situado em Seropédica, gerido em parceria da Universidade Federal Rural do Rio de Janeiro (UFRRJ) com a prefeitura deste município, e o CIEP 041- Vital Brazil, no bairro de Luiz Caçador localizado em São Gonçalo.

A partir destes dados levantados pelo questionário, foi possível refletir e entender melhor as representações sobre as referidas cidades, que, embora façam parte da região metropolitana do Rio de Janeiro, apresentam dinâmicas e discursos próprios que precisam ser desvendadas e analisados. 
Nesse sentido, as apreensões e representações dos(as) educandos(as) sobre as cidades pesquisadas tornaram-se um dos pontos de partida do estudo em pauta.

\section{SEROPÉDICA, NITERÓI E SÃO GONÇALO: CRUZANDO OLHARES²}

Quais são os olhares e apreensões que são construídos sobre os lugares, especificamente sobre as cidades? Quais são as representações que são acionadas por meio da linguagem ou, para além dela, e que conformam o discurso sobre a cidade, especialmente, Seropédica, Niterói e São Gonçalo? Em que medida as representações produzidas no plano do concebido permeiam o plano do vivido, mas o supera, ao mesmo tempo, como nos aponta Lefebvre (1983) nas reflexões que desenvolve sobre representações?

As respostas apresentadas por meio das quatro perguntas realizadas com estudantes do segundo ciclo do ensino fundamental, ofereceram um bom ponto de partida para pensar tais questões. Os sujeitos envolvidos com a pesquisa, como já apontado em outro momento do texto, são estudantes do ensino fundamental em que a faixa etária se situa, normalmente, entre doze e quinze anos, embora, vale ressaltar que a relação idade-série nem sempre corresponde a esse recorte etário na sala de aula. A escola envolve sujeitos e suas trajetórias que são atravessadas por questões raciais, de gênero e sociais e que se expressam na relação idade-série.

Iniciaremos com as análises das respostas dos vinte e seis (26) estudantes do Instituto Estadual Ismael Coutinho - EPIC, escola localizada no bairro de São Domingos, em Niterói. No que se refere a primeira pergunta - "para você, a cidade é...? - identificamos que 8\% dos estudantes não responderam e os demais, ao responderem, tomaram como referência a cidade de maneira mais específica, ou seja, mencionaram Niterói. Estes dados revelam que, ao se abordar o conteúdo de cidade na sala de aula, faz-se necessário dialogar com o espaço de vivência, ou seja, com a cidade vivida, pois, do contrário, a cidade se torna uma abstração.

Partindo desse quadro nos detivemos na segunda pergunta qual seja: para você, Niterói é...?". Nesse sentido, $60 \%$ dos estudantes consultados considerou a cidade de Niterói uma "cidade sorriso", "boa para se viver", "bastante bonita e quente" e "um bom lugar para crescer" e 38\% dos entrevistados apontaram que esta cidade - tanto no questionário de caráter abrangente quanto de caráter específico - era "perigosa", "perigosa e grande" e "poluída e violenta".

\footnotetext{
2. A primeira versão dessa pesquisa foi apresentada no Encontro Nacional dos Geógrafos Brasileiros (2018) e compõe os anais do referido encontro SILVA, Adriana, Carvalho; BEZERRA, Amélia Cristina Alves . Trajetórias, Encontros e Caminhos: apresentando a pesquisa "Leituras sobre as espacialidades das cidades e suas representações na sala de aula" In: XIX Encontro Nacional de Geógrafos: Escalas, conflitos socioespaciais e crise estrutural da nova geopolítica mundial, João Pessoa. Anais, 2018, p. 1-7.
} 
Quando indagados a respeito de questões mais específicas, ou seja, a quarta pergunta - "o que você gosta na sua cidade...? - 20\% dos pesquisados não responderam. Entre estes, os estudantes que se omitiram em expressar suas representações da cidade de maneira geral. Dentro deste percentual, também estão inclusos os que apontaram a cidade como "perigosa". Já 80\% dos entrevistados apontaram diversificados lugares que gostavam dentro da cidade. Os mais mencionados foram "o centro de Niterói", "o shopping", "as praias" e "as praças". A "paisagem da cidade" foi citada no mesmo grau de importância, assim como, em menor proporção, o "campo de futebol”, “o mercado" e a "favela".

Nos preocupou o fato de $20 \%$ dos(as) estudantes não apontarem nenhum lugar com o qual se identifique na cidade em que vivem. Essa informação nos coloca diante das razões que têm contribuído para o silenciamento desses estudantes em relação a cidade em que vivem, nos apontando a necessidade de um desdobramento da pesquisa no sentido mais qualitativo. Afinal de contas existe um distanciamento na relação de alguns sujeitos em formação com a cidade de Niterói? Se existe, quais seriam os motivos?

Por meio dessa pesquisa, verificamos que as representações sobre a cidade são um misto de vivências dos(as) educandos(as) com a cidade e, ao mesmo tempo, um diálogo com as imagens que são veiculadas sobre Niterói. Nestas imagens, a cidade é constantemente apresentada pelos seus gestores como "cidade sorriso", "cidade de melhor qualidade de vida", etc. Esta cidade também ocupa os cenários das telenovelas em que é apresentado as suas paisagens, bem como os seus espaços construídos, como é o caso do Museu de Arte Contemporânea de Niterói - MAC, a ponte Rio-Niterói e as suas praias.

Segundo os dados do Instituto Brasileiro de Geografia e Estatística/IBGE (2010), o município de Niterói possui 496.696 habitantes e o índice de Desenvolvimento Humano Municipal (IDHM) de 0,837. Estes números posicionam o município fluminense na sétima posição em relação aos demais municípios brasileiros e a primeira posição em relação ao estado do Rio de Janeiro.

Esse IDHM de Niterói tem sido agregado às imagens e às representações construídas pelas diferentes gestões da cidade, reforçando as questões sugeridas por Lefebvre (1983). Este defende que a dimensão do espaço concebido é um dos planos de produção das representações. Isto conduz às seguintes reflexões: (i) quem produz as representações? (ii) como tais representações dialogam com os moradores da cidade, e, especificamente, com os(as) educandos(as)? e (iii) as representações oficiais são questionadas no cotidiano da sala de aula?

Tais questões precisam permear o debate sobre Niterói, pois o ideário de "melhor IDHM" e de "Cidade Sorriso" esconde, muitas vezes, as dificuldades de sobreviver numa cidade onde o 
imposto territorial urbano (IPTU) é um dos mais caros do Brasil, dificultando o aceso ao solo urbano pela população de baixa renda.

Refinar os olhares na sala de aula por meio da prática da pesquisa é imprescindível, pois permite construir elementos para dialogar com os sujeitos em formação. Afinal, o espaço interessa no processo formativo.

Seguindo as respostas atribuídas a questões semiestruturadas apresentaremos e discutiremos as análises das respostas dos estudantes da unidade escolar CAIC de Seropédica. Num total de 49 estudantes participantes, $40 \%$ dos pesquisados forneceram respostas com aspectos negativos sobre Seropédica - "uma cidade de morte", "horrível", "não gosto de nada", "um lixo", "tem que melhorar muito para se tornar cidade". Apontaram, ainda, problemas como falta de infraestrutura urbana (principalmente, calçamento e iluminação), violência e presença de milicianos.

Ainda sobre esse grupo pesquisado, as respostas sobre o que mais gostavam na cidade se restringiram a respostas curtas como "nada", a "praça", uma "lanchonete" e surpreendentemente uma aluna escreveu "a praia". A referência à praia, inicialmente, pareceu deslocada. Contudo, pode ser explicada pela proximidade de Seropédica com o litoral sul do Rio de Janeiro (o conjunto de praias da região denominada Costa Verde).

Já 34\% dos estudantes preencheram esta etapa do questionário com relatos em que predominavam mais os aspectos positivos que identificavam Seropédica como "um lugar "bom", "calmo", "lindo", seguidos, no entanto, de observações complementares como "que está abandonado" ou "que precisa de cuidado". "O comércio", "a praça" e a presença da "universidade" apareceram, nestes relatos, como aspectos positivos do município que se contrapõem a violência e a falta de infraestrutura urbana citadas em resposta ao questionamento“o maior problema de sua cidade é...?”.

Vale salientar que os $26 \%$ restantes fizeram relatos em que predominaram certa neutralidade ou imparcialidade com relação às questões propostas - "cidade é um conjunto de bairros", "um lugar grande", "um lugar que tem muitas festas, muito comércio". Ao se referirem especificamente a Seropédica, para além dos problemas já apontados nos grupos de respostas anteriores no que concerne à "violência" ou à "falta de iluminação e de asfalto"; chamam a atenção respostas que identificavam o município como "lugar de moradia" ou, simplesmente, trazendo como resposta a palavra "moradia".

Nestes relatos, aparentemente neutros, não houve menção às benesses ou a outro atrativo que não fosse aquele proporcionado pelo abrigo da casa. O movimento pendular que oscila entre o "lugar do lazer e do trabalho" em contraponto ao "local de pouso" - onde se deposita o corpo cansado - e ao "lugar das ausências" é uma característica bastante consolidada para identificar as "cidades dormitório". 
Muitos municípios, da Baixada Fluminense, região à qual pertence Seropédica, são percebidos, ainda, como "cidades dormitórios", embora, tal conceito seja questionado por aqueles que vêm discutindo as dimensões teóricas-históricas que envolvem a produção das cidades. Nesse sentido, essa pesquisa revelou a necessidade de entender os níveis de afetividades dos sujeitos em formação com a cidade e, em que medida, interpretações e representações construídas sobre as cidades no Brasil atravessam as apreensões dos sujeitos em formação na sala de aula.

Seropédica é uma cidade situada em uma região estigmatizada pelos problemas socioeconômicos. Localizada na Região Metropolitana do Rio de Janeiro, compõe a já citada Baixada Fluminense, uma região marcada por níveis alarmantes de pobreza e violência. Com população de aproximadamente 84 mil habitantes, os indicadores socioeconômicos de Seropédica como o IDHM precisam ser associados a outros fatores que possam qualificar melhor este espaço. Isto porque a presença da Universidade Federal (UFRRJ) num município relativamente pequeno mascara níveis de renda e alfabetização contabilizando aqueles que não representam a condição de vida da população local e de moradia permanente.

Sendo assim, podemos afirmar que dados socioeconômicos por si só não qualificam a cidade. Rocha (2015) alerta que basta atentar ao fato de que o percentual referente ao Índice de Educação Básica (IDEB) de Seropédica está abaixo da média nacional - 3,7 numa escala que mede como 4,0 a média nacional - para entender que o seu IDHM, considerado médio ou alto $(0,713)$, precisa ser confrontado com outros referenciais (INEP, 2011). ${ }^{3}$

Ao se voltar para os dados obtidos da unidade escolar CIEP-041 no bairro Luiz Caçador em São Gonçalo, identificou-se que os 29 alunos que participaram da pesquisa de campo são oriundos de bairros próximos como Trindade, Salgueiro, Palmeiras e Itaúna. Durante a análise dos dados, as respostas da pergunta sobre a apreensão sobre a cidade, $40 \%$ dos estudantes manifestaram-se, já que alguns participantes tiveram dificuldades em responder, deixando até em branco.

Essa ausência de respostas, o "deixar em branco", nos aponta elementos para pensarmos esse distanciamento em relação ao conceito de cidade na sala de aula, pois tal como ocorreu nas respostas as perguntas feitas sobre Niterói, aqueles que responderam à questão acima se inspiraram na segunda pergunta "Para você, São Gonçalo é...?". Diversas respostas revelaram aspectos negativos do município como ser "uma cidade suja", "uma cidade que não tem nada a se fazer" e "está muito violenta". Entretanto, encontraram-se evidenciados em outras respostas aspectos positivos como uma "cidade onde tem shoppings" e "cidade com muitas praças".

\footnotetext{
${ }^{3}$ Dados retirados do Instituto Nacional de Estudos e Pesquisa Educacionais Anisio Teixeira( INEP) Disponivel em : http://inep.gov.br/sinopses-estatisticas-da-educacao-basica Data do acesso 09/04/2020.
} 
Respondida por todos, a segunda pergunta revelou múltiplas e contraditórias questões sobre a cidade. Dos que responderam de forma negativa, 50\% disseram que São Gonçalo "é uma cidade com pouca estrutura", "violenta", "com muitos lugares sujos" e "sem cuidado e tomada pela poluição do lixo deixado nas ruas". Ao mesmo tempo, apareceram 50\% de relatos que apontaram outros aspectos da cidade como "um lugar onde mora a família", "onde se brinca com meus amigos" e "de amor e respeito ao bairro".

Conseguem perceber-se as diferentes representações do estudante sobre a cidade que, ao mesmo tempo, configura-se não só em um lugar das contradições e desigualdade, como também em um lugar afetivo. Em relação à pergunta sobre o maior problema da cidade, $40 \%$ dos estudantes relataram aspectos da infraestrutura, denunciando que "as ruas estão muito ruins" e "as ruas estão com muito lixo", porque, segundo alguns, "as pessoas não se importam com a cidade".

Outra resposta recorrente foi sobre a violência. Muitos relatos (cerca de 60\%) estavam associados ao número de assaltos, além de diversos bairros ocupados pelo tráfico de drogas. Algumas das respostas foram "onde eu moro é muito violento", "o tráfico está por todo lugar de São Gonçalo" e "fico com medo de sair, porque sempre tem assalto em São Gonçalo". Alguns bairros têm sido alvos de barricadas de traficantes de drogas, de revistas da polícia e dos traficantes e por vezes de tiroteios. Parte dos estudantes da escola pesquisada tem vivido este problema. De vez em quando, seus bairros sofrem interdição policial, impossibilitando-os de irem à escola. Eles relataram que "quando tem operação no Salgueiro, muitos acabam não vindo para a escola". Esta é uma realidade em parte do estado do Rio de Janeiro.

A última questão perguntava “O que você gosta na sua cidade?". Interessante apontamento foi em relação à educação e à saúde, pois a maioria dos estudantes (70\%) alega que, apesar do descaso dos governantes e dos problemas, a cidade tem boas escolas e postos de saúde. Dessa forma, destacaram estes serviços como um ponto positivo ao falarem sobre São Gonçalo. Outra questão que chama a atenção está relacionada aos aspectos de lazer, pois $60 \%$ apontaram o shopping como sendo o lugar onde "vão ao cinema" e "encontram com os (as) amigo(as)".

As representações dos estudantes apontam para pensar que existem semelhanças e diferenças nos seus olhares sobre a cidade que foram construídos, a partir das múltiplas dimensões vividas e reveladas por meio das suas linguagens no momento da pesquisa. Alguns dos olhares vão ao encontro dos apontamentos que Souza (2011) elabora em torno do debate das cidades, especialmente, no que se refere as atividades exercidas nestes locais.

Nos dados analisados sobre São Gonçalo, foram destacadas as atividades de comércio, serviços e lazer, mostrando que os estudantes olham a cidade, a partir das suas diferentes áreas de 
atuação econômicas e, inclusive, ainda a partir da segregação espacial. Tais elementos frisados são destacados por Souza (2011) e Abreu (1999), quando pensam a produção da cidade.

Segundo os dados do IBGE Cidades (2019), São Gonçalo possui uma população estimada de 1.084 .839 e o IDHM de 0.739 (censo de 2010) e ocupa, em termos de renda per capita, a $85^{\text {a }}$ posição em relação aos demais municípios do estado do Rio de Janeiro. Esses índices são considerados altos em vista das condições de desigualdades socioeconômicas dos(as) seus moradores(as). Tais desigualdades foram apontadas nas falas dos(as) estudantes quando mencionam a falta de infraestrutura, a violência e a ausência de cuidado com a cidade.

\section{APROXIMAÇÕES DOS RESULTADOS: PENSANDO AS SINGULARIDADES, AS VIVENCIAS E AS ESCALAS ESPACIAIS QUE ENVOLVEM AS ABORDAGENS DA CIDADE NA SALA DE AULA}

Niterói, Seropédica e São Gonçalo - embora componham, junto com outras cidades, a região metropolitana do Rio de Janeiro - apresentam paisagens, vivências e experiências bem diferentes. As representações dos estudantes contribuíram para um certo desvelamento das singularidades das cidades em que vivem, apagadas, muitas vezes, pelas referencias de cidade construídas, historicamente, e ainda pelo poder da metrópole.

Ao falar do processo de urbanização brasileira, Milton Santos (2005) destaca a questão da metropolização (oligopolização) como uma das características do processo de urbanização brasileira. Nesse processo, muitas cidades ficaram enredadas e ofuscadas pelo controle da metrópole, a exemplo das cidades que compõe a região metropolitana do Rio de Janeiro.

Por meio da pesquisa conseguimos nos aproximar da dimensão do vivido dos(as) estudantes, e, ao mesmo tempo, dos discursos construídos sobre as cidades onde vivem, ou seja, o plano do concebido. A pesquisa revelou como essas duas dimensões se cruzam e se revelam por meio das representações.

Lefebvre (1983, apud in Bezerra (2006)) nos alerta que entre os espaços de representação e as representações do espaço, ou seja, entre a vivência e o concebido, não há corte, ruptura ou quebra. Além disso, o movimento dialético entre essas duas dimensões do espaço nunca cessa- pois a "vivência se enche de representações, porém se livra delas, posto que é ela mesma que se representa" (LEFEBVRE, 1983, apud in BEZERRA, 2006, p.70).

No caso de Niterói, a pesquisa revelou o papel que as imagens construídas no plano do concebido exercem sobre as representações que os estudantes possuem sobre esta cidade. A imagem 
de Niterói como "a cidade sorriso", "a cidade da melhor qualidade de vida" do estado e do país, lugar de bonitas praias e uma bela paisagem, atravessa boa parte dos olhares que os estudantes possuem sobre a cidade.

Uma grande parte dos(as) sujeitos que participaram da pesquisa apontou as praias e as paisagens como os elementos que mais gostavam na cidade. Ao mesmo tempo, o centro de Niterói se destacou como o espaço de experiência destes estudantes com a cidade, revelando de certa maneira suas vivências cotidianas para além da imagem das praias, das paisagens mercantilizadas.

As concepções sobre Niterói apresentadas pelos(as) estudantes revelaram também a violência e a insegurança como os principais problemas da cidade refletindo, dessa maneira, as questões enfrentadas na escala estadual. Muito embora, tais problemas sejam vivenciados, em maior proporção, pelos(as) moradores(as) das comunidades que habitam os morros da cidade, como é o caso de boa parte dos estudantes que responderam às perguntas propostas na pesquisa.

Quanto à Seropédica, percebe-se que, na concepção sobre esta cidade, predominam, de modo geral, o sentimento de repulsa e desafeto, bem como, pouca ou nenhuma identificação com o espaço vivido. Os resultados da pesquisa, está em conformidade, de certa maneira, com os discursos que se reproduzem sobre as cidades da região da Baixada Fluminense. Revelam também a necessidade de diálogo sobre a natureza destes discursos que compõe as representações desses espaços urbanos.

A posição deste município como zona periurbana e fronteiriça da região metropolitana do Rio de Janeiro confunde os alunos na identificação de Seropédica como cidade - categoria associada por eles a elementos que simbolizam a noção de progresso (espaços em que há altos prédios, muitas luzes, centros modernizados de comércio e etc.). Simultaneamente, as representações também revelaram a cidade como abrigo. Nesses relatos e apreensões sobre Seropédica, não houve menção a outros espaços da cidade como atrativo que não fosse aquele proporcionado pelo abrigo da casa.

Tais revelações expressam como a construção das representações em torno do urbano e da cidade forma-se. Nestas representações, a ideia de progresso vinculada a elementos como presença de luzes e edificações urbanas impuseram-se como referência, inclusive nos livros didáticos, invisibilizando outras formas-conteúdos de cidades.

Já em São Gonçalo, as representações dos estudantes revelaram um misto de amor e temor pela cidade. Para alguns a cidade é apontada como "feia, horrível, suja", já para outros "boa de se morar". Nesse sentido, o olhar crítico para os problemas da cidade vem acompanhado de afeto e cuidado, pois, ao mesmo tempo em que apontam a ausência de infraestrutura, reivindicam que a população se mobilize para cuidar da cidade 
Outro ponto marcante está associado ao desejo de ver a cidade livre do tráfico de drogas, muito presente em diversos bairros, atualmente. Além disso, os estudantes querem mais segurança nos bairros para, assim, conseguirem se deslocar entre os lugares, como também desejam ruas limpas e organizadas-

As representações e apreensões apresentadas pelos estudantes sobre São Gonçalo e Seropédica parecem ser acompanhadas pela ideia da ausência, da falta que se intercalam com a ideia de abrigo e afeto. Essas questões não atravessaram as representações sobre Niterói. Tal fato conduz a pensar sobre o papel que cada uma dessas cidades exerceu na divisão territorial do trabalho e, especificamente, no processo urbanização do território fluminense.

Nesse sentido, vale mencionar um dos atributos retratados nestas cidades, sobretudo em São Gonçalo que, em determinado momento das análises urbanas, foi compreendida como "cidade dormitório". Pode-se interrogar em que medida o caráter de ser "cidade dormitório" vêm, historicamente, influenciando nas políticas urbanas, especialmente, na forma como os gestores veem a cidade. Este atributo problemático ficou expresso nas representações dos estudantes sobre São Gonçalo que cobraram a necessidade de um olhar mais cuidadoso para a cidade. Esta afirmação ratifica a compreensão, por parte dos(as) pesquisados(as), de um certo abandono da cidade no plano da gestão.

Vários têm sido os estudos que tentam romper com as representações que colocam estas cidades como "espaço dormitório", como é o caso da tese de doutoramento de Rosa (2017), que ao identificar os fatores que fortaleceram esse consenso no imaginário dos habitantes e nas políticas públicas, alerta para a relatividade do termo no caso de São Gonçalo, com destaque para a expressiva atividade industrial e a elevada aglomeração urbana desse município, sobretudo nas últimas décadas, apresentando elementos mais característicos de centralidade que de dependência.

Outros trabalhos seguem o mesmo caminho, como o de Sacramento (2017) que ao investigar como a cidade é estudada nos currículos e chama atenção para análise espacial de São Gonçalo. Para tanto, discute São Gonçalo no contexto da região metropolitana e reforça a necessidade de pensar suas paisagens e compreender os sentidos da cidade para promover uma lógica de ensinar geografia a partir do espaço vivenciado. Nessa direção, aponta os estudos de Modesto (2008) e Silva (2012) para compreendermos a necessidade de pensar a segregação socioespacial como uma das grandes questões a serem enfrentadas.

Esse percurso em direção as apreensões e representações dos estudantes sobre as cidades de Niterói, São Gonçalo e Seropédica fazem perceber algumas questões. Dentre elas: 
i) a necessidade de compreender as cidades brasileiras, suas singularidades e, portanto, a historicidade dos seus processos socioespaciais, especialmente, nas aulas de geografia, para tanto é preciso ir para além dos conteúdos curriculares. Ao mesmo tempo, é preciso lembrar que as dinâmicas urbanas impressas nas cidades são orientadas por processos mais globais que incidem sobre o território como bem nos propõe Santos (2005). Contudo, desvendar e visibilizar a dinâmica socioespacial de cada cidade que orbita em torno das metrópoles que detém o poder e o aparato técnico-informacional ajuda a compreender e tencionar as referências de cidade construídas e consolidadas no Brasil e que compõe os olhares e as representações dos nossos estudantes.

ii) o papel da dimensão escalar na produção das representações, especialmente, no plano do vivido que é atravessado por um jogo de discursos e representações construído no plano do concebido - e que se pretendem universais - a exemplo dos modelos de cidade. Esse processo, afirma, muitas vezes, os modelos hegemônicos de cidade e produz uma invisibilidade do cotidiano e a desvalorização de outras espacialidades que fogem aos padrões urbanos estabelecidos;

iii) Criar/propor metodologias envolvendo o conceito de cidade que possam dialogar com o espaço vivido, mas que, ao mesmo tempo, permitam iluminar outras realidades urbanas, possibilitando que os estudantes possam pensar de maneira mais ampla a cidade, afinal esse é o papel de um conceito.

iv) a necessidade de aproximação e compreensão das vivências dos sujeitos, suas referenciais de cidade por meio da pesquisa. Nesse sentido, Freire (2006) já lembrava que não existe ensino sem pesquisa. Por meio da pesquisa desvendamos o mundo e a nós mesmos.

\section{REFERÊNCIAS}

ABREU, Maurício Almeida de. Geografia Histórica do Rio de Janeiro (1502-1700). 1. ed. Rio de Janeiro: Andrea Jakobson Estúdio e Prefeitura do Município do Rio de Janeiro, 2010. v. 2. 900 p.

ABREU, Maurício Almeida de. Evolução Urbana do Rio de Janeiro. $3^{\text {a }}$. ed. Rio de Janeiro: Iplanrio, 1999. v. 1. 156 p.

ABREU, Maurício Almeida de. O estudo geográfico da cidade no Brasil: Evolução e avaliação (Contribuição à história do pensamento geográfico brasileiro). In: CARLOS, Ana Fani A. (Org.). Os caminhos da reflexão sobre a cidade e o urbano. São Paulo: Edusp, 1994, p. 199-322.

BEZERRA, Amélia Cristina A. Pelas margens da cidade e no meio da festa: A (re) invenção das Festas e da Identidade no espaço urbano de Mossoró - RN. Defendida em 2006, 208 p. Doutorado em Ordenamento Territorial do Programa de Pós Graduação em Geografia. Universidade Federal Fluminense. Niterói, 2006. 
DAL-FARRA, Rossano André; LOPES, Paulo Tadeu C. Métodos mistos de pesquisa em Educação: pressupostos teóricos. In: Nuances, v. 24, p. 67-80, 2013. Disponível em: https://revista.fct.unesp.br/index.php/Nuances/article/view/2698. Acesso em 20 mai. 2020.

FREIRE, Paulo. Pedagogia da Autonomia: saberes necessários à prática educativa. São Paulo: Paz e Terra, 2006.

HALL, S. Cultura e Representação. Tradução: Daniel Miranda \& William Oliveira - Rio de Janeiro: Ed. PUC Rio: Ed. Apicuri. 2016.

IBGE. São Gonçalo, 2020. In Cidades Disponível em https://cidades.ibge.gov.br/brasil/rj/saogoncalo/panorama. Acesso em 20 nov 2019.

LEFEBVRE, Henry. La presencia y la ausencia. Contribución a la teoría de las representaciones. México, D.F. Fundo de Cultura Econômica, 1983.

. The production of space. Oxford (R.U.) e Cambridge (EUA), 1991.

. O direito à cidade. São Paulo: Centauro, 2001.

MASSEY, Doreen B. Pelo espaço: uma nova política da espacialidade. Tradução Hilda Pareto Maciel e Rogério Haesbaert. Rio de Janeiro: Bertrand Brasil, 2008.

PORTO-GONÇALVES, Carlos Walter. A geograficidade do social: uma contribuição para o debate metodológico para os estudos de conflitos e movimentos sociais na América Latina. In: Revista Eletrônica da Associação dos Geógrafos Brasileiros - Seção Três Lagoas/MS, v. 1, n. 3, p. 5-26, maio, 2006. Disponível em: https://periodicos.ufms.br/index.php/RevAGB/article/view/1344. Acesso em 20 abr. 2020.

ROCHA, Andre Santos. Os Desafios de Seropédica no contexto metropolitano fluminense. In: ROCHA, André Santos; OLIVEIRA, Leandro Dias; BARROS, Regina Cohen. (org). A Geografia de Seropédica: Reflexões Teóricas e Práticas Educativas no PIBID. Nova Iguaçu, RJ: Entorno, 2015.

ROSA, Daniel Pereira. De cidade-dormitório à centralidade da grande cidade periférica: trabalho, consumo e vida de relações de São Gonçalo na Região metropolitana do Rio de Janeiro. 297 p. Tese de doutorado. Faculdade de Filosofia, Letras e Ciências Humanas da Universidade do Estado de São Paulo. São Paulo, 2018.

SACRAMENTO, Ana Claudia Ramos. Ensino de Geografia e a Cidade de São Gonçalo. 1. ed. Seropédica: EDUR, 2017 [e-book]. v. 1. Disponível em: http://r1.ufrrj.br/edur/loja/ensino-degeografia-e-a-cidade-de-sao-goncalo/. Acesso em: 20 fev. 2020.

SANTOS, Milton. A natureza do espaço: técnica e tempo, razão e emoção. São Paulo: Hucitec, 1996.

SANTOS, Milton. A urbanização brasileira. $5^{\text {a }}$ ed. Edusp., 2005. 
SANTOS, José Luís G. dos et al. Integração entre dados quantitativos e qualitativos em uma pesquisa de métodos mistos. In: Textos \& Contexto Enfermagem, v. 26, p. 1-9, 2017. Disponível em http://www.scielo.br/pdf/tce/v26n3/0104-0707-tce-26-03-e1590016.pdf. Acesso em: 20 mar. 2019.

SILVA, Adriana Carvalho; BEZERRA, Amélia Cristina Alves . Trajetórias, Encontros e Caminhos: apresentando a pesquisa Leituras sobre as espacialidades das cidades e suas representações na sala de aula In: XIX Encontro Nacional de Geógrafos: Escalas, conflitos socioespaciais e crise estrutural da nova geopolítica mundial. João Pessoa. Anais... João Pessoa: AGB, 2018, p. 1-7. Disponível em: http://www.eng2018.agb.org.br/resources/anais/8/1533675157_ARQUIVO_texto_ENG_Adriana_ Amelia.pdf. Acesso em 20 abr. 2020.

SOUZA, Marcelo Lopes de. ABC do desenvolvimento urbano. $6^{\text {a }}$ ed. Rio de Janeiro: Bertrand Brasil, 2011. 